\title{
Guidelines for dementia or Parkinson's disease with depression or anxiety: a systematic review
}

\author{
Zahra Goodarzi ${ }^{1,2,10^{*}}$, Bria Mele ${ }^{1}$, Selynne Guo ${ }^{3}$, Heather Hanson ${ }^{1,4}$, Nathalie Jette ${ }^{1,5,6}$, Scott Patten ${ }^{1,8,9}$,
} Tamara Pringsheim ${ }^{1,5,6,7}$ and Jayna Holroyd-Leduc ${ }^{1,2}$

\begin{abstract}
Background: Depression and anxiety remain under-diagnosed and under-treated in those with neurologic diseases such as dementia or Parkinson's Disease (PD). Our objectives were to first, to provide a synthesis of high quality guidelines available for the identification and management of depression or anxiety in those with dementia or PD. Second, to identify areas for improvement for future guidelines.

Methods: We searched MEDLINE, PsycINFO, and EMBASE (2009 to July 24, 2015), grey literature (83 sources; July 24Sept 6, 2015), and bibliographies of included studies. Included studies were evaluated for quality by four independent reviewers the AGREE II tool. Guideline characteristics, statements and recommendations relevant to depression or anxiety for dementia and PD were then extracted. (PROSPERO CRD: 42016014584)

Results: 8121 citations were reviewed with 31 full text articles included for assessment with the AGREE II tool. 17 were of sufficient quality for inclusion. Mean overall quality scores were between 4.25 to 6.5 . Domain scores were lowest in the areas of stakeholder involvement, applicability, and editorial independence.

Recommendations for the screening and diagnosis of depression were found for PD and dementia. There was little evidence to guide diagnosis or management of anxiety. Non-pharmacologic therapies were recommended for dementia patients. Most advocated pharmacologic treatment for depression, for both PD and dementia, but did not specify an agent due to lack of evidence.
\end{abstract}

Conclusions: The available recent high quality guidelines outline several recommendations for the management of comorbid depression or anxiety in PD or dementia. However there remain significant gaps in the evidence.

Keywords: Parkinson's Disease, Dementia, Depression, Anxiety, Guidelines

\section{Background}

Persons experiencing neurologic disorders, such as dementia or Parkinson's disease (PD), and depressive or anxiety disorders have poorer outcomes with reduced quality of life, poor functional status and worsened cognition [1-8].

It is estimated that the prevalence of depression in dementia is approximately $25 \%$ with anxiety occurring in up to $75 \%[7,9-11]$. In $\mathrm{PD}$, approximately $17 \%$ of

\footnotetext{
* Correspondence: zahra.goodarzi@albertahealthservices.ca

'Department of Community Health Sciences, University of Calgary, Calgary, Canada

${ }^{2}$ Department of Medicine, University of Calgary and Alberta Health Services, Calgary, Canada

Full list of author information is available at the end of the article
}

patients experience major depression and anxiety between 3.6 to $40 \%[2,12]$.

Despite awareness of these comorbidities, depression and anxiety remain under-diagnosed and under-treated in those with neurologic diseases [1, 3, 13-17]. Only $20 \%$ of PD patients diagnosed with depression receive therapy [18]. This represents a significant knowledge-topractice gap. One way to address this is through the use of Clinical Practice Guidelines (CPGs) [19]. CPGs synthesize available evidence based on a systematic review of the literature, clinical expertise and patient preferences [19]. CPGs are targeted at practitioners who apply the recommendations to clinical decision-making and reduce disparities in care [19-22]. 
Thus, in the setting of PD and dementia, CPGs should enable the appropriate management of depression and anxiety [23-26]. Despite available CPGs, these disorders remain under-managed, suggesting these CPGs are underused or lack sufficient recommendations [26-28]. Multiple available guidelines of varied quality leads to uncertainty as to which CPGs should be used in practice. Our primary aim is to synthesize the high-quality evidence-based CPGs available for diagnosis, and management of depression or anxiety in those with dementia or PD. We chose to summarize and evaluate guidelines as the majority of physicians will use CPGs as a tool to review evidence and inform practice. Secondarily we aim to, identify areas gaps within the existing guidelines to inform future guideline development. This provides a broad over view of evidence in the area and identifies areas for further study and development.

\section{Methods}

The study protocol follows the recommendations provided by the Preferred Reporting Items for Systematic Reviews and Meta-Analyses (PRISMA) - Protocols Statement [29] and guidelines and the protocol was registered with PROSPERO [30] (CRD: 42016014584).

\section{Search strategy}

The literature search was developed in conjunction with an experienced librarian (DL) and was verified independently by a second librarian (HLR), using the Peer Review of Electronic Search Strategies (PRESS) methodology [31]. Any recommendations were incorporated into the final search.

Databases included MEDLINE, EMBASE, and PsycINFO. Clusters of terms (controlled vocabulary and key words) were used to search each database; these include dementia, Parkinson's disease, depression, anxiety and CPGs (Additional file 1: Box S1). The search was completed by cluster, first searching the terms in each cluster (combined with the Boolean operator 'OR') and keyword searches of abstracts and titles. The clusters were then combined with 'AND'. We searched for several pathological variants of dementia including Alzheimer's disease, vascular, frontotemporal, Lewy Body disease, Huntington's Disease, CADASIL, primary progressive aphasia, and Creutzfeldt Jakob (Additional file 1: Box S1). We included relevant derivatives of terms or broad key words related to depressive or anxiety disorders (Additional file 1: Box S1).

This was augmented by a search of the grey literature (Additional file 2: Table S1). This search was limited from 2009 to search date, such that we would only capture CPGs developed within the past 5 years; given the evidence that CPGs may become out of date after only 3 years [32]. All languages were included in this search.

\section{Selection \& eligibility}

All citations were reviewed for eligibility by two independent authors; citations meeting initial eligibility criteria were included in full text review. If there was disagreement at the abstract stage, the full article was pulled for review. Bibliographies for all included articles were searched. If multiple CPGs were identified from a single agency on the same topic the most recent was used.

At the first stage of abstract review, any article that represented a guideline for PD or dementia was included. Eligibility at the full text stage required that the CPGs included at least one recommendation related to depression and/or anxiety in patients with PD and/or dementia. The kappa statistic was used to quantify interrater reliability.

For non-English articles that met eligibility at the full text stage, the language was determined using online translation software. Citations were translated using the online (Google translate) function to determine if an article was a guideline. When included, the documents were searched using translated relevant terms; for example, if a guideline pertained to PD in the abstract, the text was searched for depression or anxiety (and all translated synonyms). If those criteria were met, the full guideline was translated and reviewed.

\section{Assessment of quality}

The Appraisal of Guidelines Research \& Evaluation (AGREE II) tool was used to assess guideline quality [33]. This tool was designed to evaluate guideline quality and to aid in guideline development and reporting [33]. The tool includes 6 domains covering scope and purpose, stakeholder involvement, rigour of development, clarity of presentation, applicability and editorial independence [33]. Within each domain there are between 2 to 8 questions, to a total of 23 [33]. Each item is rated from 1 (not included or very poorly reported) to 7 (exceptional reporting of all criteria outlined in the AGREE II Manual) [33].

Each domain was scored independently by four reviewers, along with the assignment of an overall score. An initial assessment of 5 citations was done and compared across all 4 reviewers [33]. The 4 reviewers met to discuss discrepancies and address questions about rating, before the remainder of the guidelines were reviewed and scored. This also served to ensure that all raters were aligned in their understanding of the AGREE II items. Any further discrepancies were resolved by discussion.

Domain scores pooled across the 4 assessors were calculated, as outlined in the AGREE II user manual [33]. The higher score indicates a higher quality across rated items. It has been demonstrated that the quality across 
the AGREE II domains predicts guideline implementation [33]. The mean overall quality scores with standard deviations (SD) were calculated, as well as for each domain item. CPGs with a mean overall quality score 5 or greater were assigned at least moderate quality and included in further analysis. CPGs with a score below 3 were excluded due to low quality. A score less than 5 but greater than 3 were re-evaluated and inclusion status was decided by consensus.

\section{Data extraction \& synthesis of evidence}

Guideline characteristics were extracted by one author (ZG) and independently verified by a second author (BM). Items extracted included the primary conditions covered, region/organizations, number of committee members, numbers of references, and sources of funding.

Two independent reviewers then extracted relevant recommendations (ZG, BM). Specifically, guidelines were searched for any mention of relevant recommendations and supporting text or statements. Three authors reviewed the extracted recommendations (ZG, BM and $\mathrm{JHL}$ ). Recommendations were compiled across the guidelines into relevant categories and subcategories, and reported using descriptive statistics including the quality, number of guidelines supporting the statement and subpopulations included. As the evidence in the guidelines is represented by practice recommendations, it was not amenable to meta-analysis. The main output of this systematic review was an appraisal of the quality of all guidelines pertaining to comorbid depression or anxiety in PD or dementia, and a synthesis of the recommendations across the different guidelines. Data were analyzed using STATA 13.1 (Stata Corp. College Station, TX).

\section{Results}

\section{Study selection}

The database search generated 4441 citations after duplicates were removed, with a further 3681 citations identified from the grey literature (Fig. 1). When screened for eligibility, 360 citations met criteria for full text review ( $\kappa=0.88,95.7 \%$ agreement). At this stage most articles were excluded because they were not relevant $(n=218)$, were not guidelines, or were unrelated guidelines. Other common reasons for exclusion at the full text stage were being out of the date range $(n=33)$ or a duplicate $(n=35)$. Excluded citations also included 26 mental health guidelines that did not address PD or dementia. Similarly there were 5 PD and 9 dementia guidelines that did not address depression or anxiety. The dementia guidelines primarily pertained to Alzheimer's disease, vascular dementia, general dementia care and one referred to Lewy Body Disease. Of these articles, 4 were identified to be summary documents of included guidelines and were used as supplemental material to these included guidelines. Twenty-six CPGs met all eligibility criteria and were evaluated using the AGREE II tool, of which 17 met the quality cut off for inclusion.

\section{Guideline characteristics}

The 17 included guidelines addressed PD $(n=5)$, dementia $(n=8)$ and mental health $(n=4)$ CPGs (Table 1$)$. They included recommendations from many regions, including Canada $(n=2)$, USA $(n=3)$, Pan-European $(n=4)$, UK $(n=2)$, Scotland $(n=1)$, Spain $(n=2)$, South Korea $(n=1)$ and international $(n=2)$. The associations or organizations are outlined in Table 1. All guidelines used a method for grading the evidence (Additional file 3: Figure S1). Most guidelines were funded through government or non-commercial funding; only two CPGs had some pharmaceutical funding.

\section{Study quality}

These 26 CPGs were assessed for quality using all 23 items across the 6 domains of the AGREE II tool. Nine guidelines were excluded for low quality. Six were excluded with an overall mean rating ranging from 2.25 to 3.75 . Three had ratings of $4-4.5$, where decision to exclude was by consensus. A low rating was typically due to unclear methods; thus scoring low on rigour of development, applicability and editorial independence. Authors of guidelines were contacted for more information in the case that an item was unclear and responses were incorporated in the quality assessment.

The 17 included guidelines had mean overall scores from 4 to 6.5 (Table 2). When examining the individual domain scores, the highest rated domain was Domain 4: Clarity of Presentation (mean score 77.0; SD 11.4). This was followed by Domain 1: Scope and Purpose (mean score 72.1; SD 12.1). Domain 5: Applicability was the lowest rated domain (mean score 41.5; SD 22.6). Stakeholder involvement (Domain 2) also had a low score (mean score 54.5; SD 23.3).

The mean rating across each question in the domain scores were also examined to explore differences between domains (Additional file 4: Table S2). Question one pertaining to the overall objectives was the highest rated item at 5.88 (SD 0.61), followed by link between evidence and recommendations at 5.78 (SD 0.51). The lowest rated item was providing a procedure for updating the guideline is provided, with a mean rating of 3.16 (SD 1.73). The views and preferences of the target population have been sought was also rated poorly with a mean score of 3.25 (SD 1.92). All items in Domain 5 had low mean scores, ranging between 3.27 (SD 1.46) for resource implications and 3.72 (SD 1.53) for advice on putting recommendations into practice. 


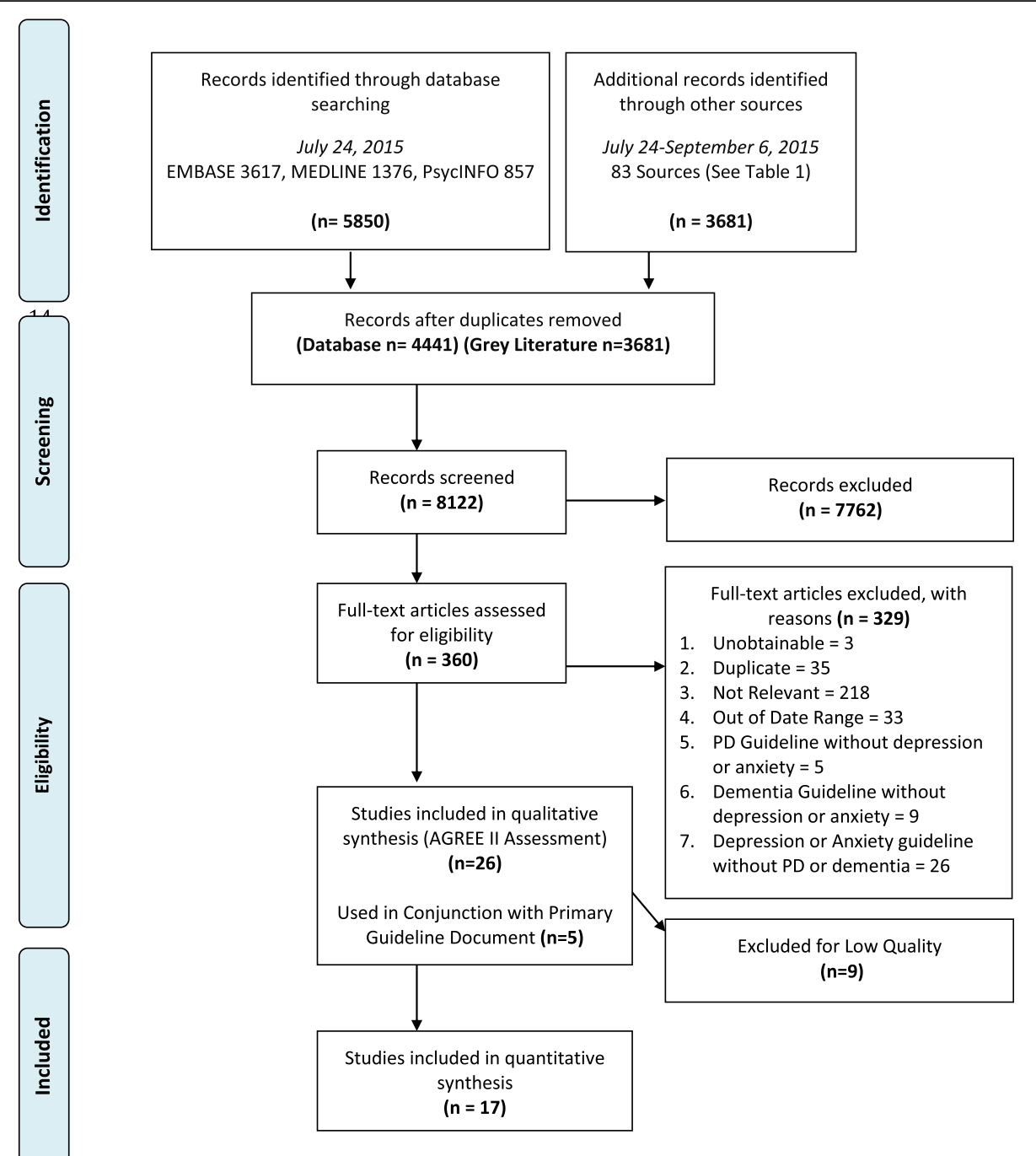

Fig. 1 PRISMA Flow Diagram

\section{Guideline recommendations}

The details of extracted recommendations are summarized in the Table 3 for PD and Table 4 for dementia. 21 categories of recommendations were extracted in total.

\section{Parkinson's disease recommendations}

Only two guidelines discussed anxiety in those with PD $[34,35]$. These stated there was little evidence for either the diagnosis or treatment of anxiety in $\mathrm{PD}$, and that there was insufficient evidence for the treatment of anxiety with levodopa [34, 35].

There were clear recommendations surrounding the diagnosis of depression in PD [34, 37, 38]. Clinicians should have a low threshold for the diagnosis of depression in PD given the difficulties making a diagnosis [34]. Use of a validated tool for detecting depression (or neuropsychiatric symptoms) was advocated by two guidelines, with varying levels of recommendations [37, 38]. Tools that were recommended include the HDRS, the MADRS or the UPDRS-Part 1 Non-Motor, among others [37, 38]. The diagnosis should be made based on a clinical interview and not based on the tool alone and should seek collateral information from carers [37].

Antidepressant therapy is recommended, however there is little evidence to support one agent over another $(n=2)[37,39]$. Additionally, the choice of an agent must be individualized $(n=1)$ and the practitioner should consider side effects and drug interactions prior to initiation [34]. There have been prior studies on the tricyclic antidepressants (TCAs), specifically amitriptyline, and although they were beneficial for mood, this was offset by the side effects $(n=3)[34,37,39]$. One guideline noted that selective serotonin reuptake inhibitors (SSRIs) showed some benefit in uncontrolled studies [39, 40], but noted that the SSRIs could worsen PD symptoms of restless legs (RLS), periodic limb movement (PLM) and 
Table 1 Guideline Characteristics

\begin{tabular}{|c|c|c|c|c|c|c|c|c|c|c|}
\hline Author (year) & Organiz-ation & Primary condition ${ }^{a}$ & Focus & $\begin{array}{l}\text { Region of } \\
\text { origin }\end{array}$ & $\begin{array}{l}\text { \# of Committee } \\
\text { membersi }\end{array}$ & \#of Refs & $\begin{array}{l}\text { Systematic } \\
\text { search }(\mathrm{Y} / \mathrm{N})\end{array}$ & $\begin{array}{l}\text { Grading of } \\
\text { evidence }(\mathrm{Y} / \mathrm{N})\end{array}$ & $\begin{array}{l}\text { Funding } \\
(\mathrm{NS}, \mathrm{P}, \mathrm{NC}, \mathrm{G})^{j}\end{array}$ & $\begin{array}{l}\text { Mean quality } \\
\text { score }\end{array}$ \\
\hline $\begin{array}{l}\text { Zesiewicz et al. } \\
\text { (2010) [35] }\end{array}$ & $\begin{array}{l}\text { The American Academy of Neurology } \\
\text { (AAN) }\end{array}$ & PD & Treatment & USA & 9 & 40 & Y & Y & NC & 4.5 \\
\hline $\begin{array}{l}\text { No Author } \\
(2010)^{b}[37]\end{array}$ & $\begin{array}{l}\text { Scottish Intercollegiate Guidelines } \\
\text { Network (SIGN) }\end{array}$ & PD & Diagnosis Treatment & Scotland & 20 & 189 & Y & Y & G & 6 \\
\hline $\begin{array}{l}\text { Grimes et al. } \\
(2012)^{c}[34]\end{array}$ & $\begin{array}{l}\text { Canadian Neurological Sciences Federation } \\
\text { (CNSF) \& Parkinson Society Canada }\end{array}$ & PD & Diagnosis Treatment & Canada & 22 & 62 & Y & Y & $N C \& P$ & 6.5 \\
\hline $\begin{array}{l}\text { Berardelli et al. } \\
\text { (2013) [38] }\end{array}$ & $\begin{array}{l}\text { European Federation of Neurological } \\
\text { Societies \& Movement Disorder Society—- } \\
\text { European Section (EFNS-MDS-ES) }\end{array}$ & PD & Diagnosis & Europe & 25 & 245 & Y & Y & $N S^{h}$ & 5 \\
\hline $\begin{array}{l}\text { Ferreira et al. } \\
\text { (2013) [40] }\end{array}$ & $\begin{array}{l}\text { European Federation of Neurological } \\
\text { Societies \& Movement Disorder Society_- } \\
\text { European Section (EFNS-MDS-ES) }\end{array}$ & PD & Treatment & Europe & 22 & 363 & Y & Y & NC & 4.5 \\
\hline $\begin{array}{l}\text { Hort et al. } \\
\text { (2010) [47] }\end{array}$ & $\begin{array}{l}\text { European Federation of Neurological } \\
\text { Societies (EFNS) }\end{array}$ & Dementia & Diagnosis Treatment & Europe & 8 & 100 & Y & Y & NC & 4.25 \\
\hline $\begin{array}{l}\text { No Author } \\
\text { (2010) [42] }\end{array}$ & $\begin{array}{l}\text { Ministry of Health, Social Services and } \\
\text { Equality \& Agency for Health Quality } \\
\text { and Assessment of Catalonia (AIAQS) }\end{array}$ & Dementia & Diagnosis Treatment & Spain & 67 & 688 & Y & Y & $N C \& G$ & 5.75 \\
\hline $\begin{array}{l}\text { No Author } \\
(2011)^{d}[41]\end{array}$ & $\begin{array}{l}\text { National Institute for Health and Care } \\
\text { Excellence, National Collaborating } \\
\text { Centre for Mental Health, British } \\
\text { Psychological Society \& The Royal } \\
\text { College of Psychiatrists (NICE) }\end{array}$ & Dementia & Diagnosis \& Treatment & UK & 28 & $N N^{h}$ & Y & Y & $N C \& G$ & 6.5 \\
\hline $\begin{array}{l}\text { Ihl et al. } \\
\text { (2011) [44] }\end{array}$ & $\begin{array}{l}\text { World Federation of Societies of } \\
\text { Biological Psychiatry (WFSBP) }\end{array}$ & Dementia & Treatment & International & 39 & $215^{f}$ & Y & Y & NC & 4.5 \\
\hline $\begin{array}{l}\text { No Author } \\
\text { (2011) [43] }\end{array}$ & $\begin{array}{l}\text { Clinical Research Centre for } \\
\text { Dementia (CRCD) }\end{array}$ & Dementia & Diagnosis & South Korea & 20 & $N N^{h}$ & Y & Y & G & 5.25 \\
\hline $\begin{array}{l}\text { O'Brien et al. } \\
\text { (2011) [60] }\end{array}$ & $\begin{array}{l}\text { British Association of } \\
\text { Psychopharmacology (BPA) }\end{array}$ & Dementia & Treatment & UK & 16 & $148^{f}$ & $\mathrm{~N}$ & Y & $N C \& P$ & 4 \\
\hline $\begin{array}{l}\text { Sorbi et al. } \\
\text { (2012) [45] }\end{array}$ & $\begin{array}{l}\text { European Federation of Neurological } \\
\text { Societies \& European Neurological } \\
\text { Society (EFNS-ES) }\end{array}$ & Dementia & Diagnosis Treatment & Europe & 17 & 189 & Y & Y & NC & 4.5 \\
\hline $\begin{array}{l}\text { Gauthier et al } \\
(2012)^{\mathrm{e}}[50]\end{array}$ & $\begin{array}{l}\text { Canadian Consensus Conference } \\
\text { on the Diagnosis and Treatment } \\
\text { of Dementia (CCCDTD4) }\end{array}$ & Dementia & Diagnosis Treatment & Canada & 38 & 19 & Y & Y & NC & 5.5 \\
\hline \multirow[t]{2}{*}{$\begin{array}{l}\text { Gelenberg et al. } \\
(2010)^{9}[39]\end{array}$} & $\begin{array}{l}\text { American Psychiatric Association } \\
\text { (APA) }\end{array}$ & Depression & Treatment & USA & 7 & 1170 & Y & Y & NC & 4.75 \\
\hline & World Health Organization (WHO) & Mental Health & Diagnosis Treatment & International & 29 & 36 & Y & Y & $N C \& G$ & 5.5 \\
\hline
\end{tabular}


Table 1 Guideline Characteristics (Continued)

\begin{tabular}{|c|c|c|c|c|c|c|c|c|c|c|}
\hline \multicolumn{11}{|l|}{$\begin{array}{l}\text { Dua et al. } \\
\text { (2011) [49] }\end{array}$} \\
\hline $\begin{array}{l}\text { No Author } \\
\text { (2012) [46] }\end{array}$ & $\begin{array}{l}\text { Ministry of Health, Social Services and } \\
\text { Equality \& Galician Health Technology } \\
\text { Assessment Agency (Availia-T) }\end{array}$ & Suicide & Diagnosis Treatment & Spain & 24 & 683 & Y & Y & $N C \& G$ & 5 \\
\hline $\begin{array}{l}\text { Mitchell et al. } \\
\text { (2013) [48] }\end{array}$ & $\begin{array}{l}\text { Institute for Clinical Systems } \\
\text { Improvement (ICSI) }\end{array}$ & Depression & Diagnosis Treatment & USA & 14 & 331 & Y & Y & NC & 5.75 \\
\hline
\end{tabular}

a Dementia guidelines primarily included Alzheimer's disease, vascular dementia, general dementia care and one referred to Lewy Body Disease

${ }^{b}$ Includes Grosset et al. [54]

' Includes Patel et al. [61]

Originally created in 2007 and updated in 2011

e Includes Moore et al. [62], Herrman et al. [63]

${ }^{\mathrm{f}}$ Number counted from the text

${ }^{\mathrm{g}}$ Includes Recommendations Referenced in Rabin et al. [64]

${ }^{\mathrm{h}}$ NS: Not Stated, NN: Not Numbered

i Committee members-extracted from paper as listed (e.g. authors listed, guideline development/working groups etc)

jNC: Non-Commercial, G: Government, Pharmaceutical, NS: Not Stated
References: The American Academy of Neurology (AAN) [35], Scottish Intercollegiate Guidelines Network (SIGN) [37, 54], Canadian Neurological Sciences Federation (CNSF) [34], Parkinson's Society Canada [34],

European Federation of Neurological Societies (EFNS) ( $n=4)$ [38, 40, 45, 47], Movement Disorders Society-European Section (MDS-ES) [38, 40], National Institute for Health and Care Excellence (NICE) [41], Ministry of

Health, Social Services and Equality \& Agency for Health Quality and Assessment of Catalonia (AIAQS) [42], British Psychological Society [41], The Royal College of Psychiatrists [41], World Federation of Societies of Bio-

Health, Social Services and Equality \& Agency for Health Quality and Assessment of Catalonia (AIAQS) [42], British Psychological Society [41], The Royal College of Psychiatrists [41], World Federation of Societies of Bio-
logical Psychiatry (WFSBP) [44], Clinical Research Centre for Dementia (CRCD), British Association of Psychopharmacology (BPA) [60], European Neurological Society, Canadian Consensus Conference on the Diagnosis

logical Psychiatry (WFSBP) [44], Clinical Research Centre for Dementia (CRCD), British Association of Psychopharmacology (BPA) [60], European Neurological Society, Canadian Consensus Conference on the Diagnosis
and Treatment of Dementia (CCCDTD4) [50], American Psychiatric Association (APA) [39], World Health Organization (WHO) [49], Ministry of Health, Social Services and Equality \& Galician Health Technology Assessment Agency (Availia-T) [46] and the Institute for Clinical Systems Improvement (ICSI) [48] 
Table 2 Domain scores from AGREE II evaluation

\begin{tabular}{|c|c|c|c|c|c|c|}
\hline $\begin{array}{l}\text { Guideline } \\
\text { (year) }\end{array}$ & $\begin{array}{l}\text { Domain } 1 \text { score } \\
\text { scope \& purpose }\end{array}$ & $\begin{array}{l}\text { Domain } 2 \text { score } \\
\text { stakeholder involvement }\end{array}$ & $\begin{array}{l}\text { Domain } 3 \text { score } \\
\text { rigour of development }\end{array}$ & $\begin{array}{l}\text { Domain } 4 \text { score } \\
\text { clarity of presentation }\end{array}$ & $\begin{array}{l}\text { Domain } 5 \\
\text { score applicability }\end{array}$ & $\begin{array}{l}\text { Domain } 6 \text { score } \\
\text { editorial independence }\end{array}$ \\
\hline \multicolumn{7}{|l|}{ Parkinson's Disease } \\
\hline $\begin{array}{l}\text { Zesiewicz et al. } \\
\text { (2010) [35] }\end{array}$ & 56.9 & 29.2 & 64.6 & 72.2 & 17.7 & 79.2 \\
\hline $\begin{array}{l}\text { SIGN } \\
(2010)^{\mathrm{a}}[37]\end{array}$ & 80.6 & 80.6 & 72.9 & 91.7 & 72.9 & 22.9 \\
\hline $\begin{array}{l}\text { Grimes et al. } \\
(2012)^{c}[34]\end{array}$ & 70.8 & 95.8 & 90.6 & 87.5 & 60.4 & 58.3 \\
\hline $\begin{array}{l}\text { Berardelli et al. } \\
\text { (2013) [38] }\end{array}$ & 72.2 & 19.4 & 47.9 & 86.1 & 12.5 & 6.3 \\
\hline $\begin{array}{l}\text { Ferreira et al. } \\
\text { (2013) [40] }\end{array}$ & 47.2 & 15.3 & 43.2 & 66.7 & 6.25 & 20.8 \\
\hline \multicolumn{7}{|l|}{ Dementia } \\
\hline $\begin{array}{l}\text { NICE } \\
(2011)^{\mathrm{b}}[41]\end{array}$ & 83.3 & 81.9 & 86.5 & 87.5 & 64.6 & 47.9 \\
\hline $\begin{array}{l}\text { Hort et al. } \\
\text { (2010) [47] }\end{array}$ & 58.3 & 38.9 & 54.2 & 66.7 & 25.0 & 62.5 \\
\hline $\begin{array}{l}\text { AIAQS } \\
\text { (2010) [42] }\end{array}$ & 87.5 & 69.4 & 73.4 & 84.7 & 57.3 & 79.2 \\
\hline $\begin{array}{l}\text { Ihl et al. } \\
\text { (2011) [44] }\end{array}$ & 68.1 & 38.9 & 57.8 & 48.6 & 19.8 & 64.6 \\
\hline $\begin{array}{l}\text { CRCD } \\
(2011) \text { [43] }\end{array}$ & 86.1 & 62.5 & 74.5 & 81.9 & 51.0 & 54.2 \\
\hline $\begin{array}{l}\text { O'Brien et al } \\
\text { (2011) [60] }\end{array}$ & 59.7 & 63.9 & 46.4 & 76.4 & 20.8 & 68.8 \\
\hline $\begin{array}{l}\text { Sorbi et al. } \\
\text { (2012) [45] }\end{array}$ & 68.1 & 38.9 & 53.7 & 65.3 & 26.0 & 62.5 \\
\hline $\begin{array}{l}\text { Gauthier et al } \\
(2012)^{d}[50]\end{array}$ & 73.6 & 70.8 & 70.8 & 87.5 & 50.0 & 79.2 \\
\hline \multicolumn{7}{|l|}{ Mental Health } \\
\hline $\begin{array}{l}\text { Gelenberg et al. } \\
\text { (2010) [39] }\end{array}$ & 68.1 & 41.7 & 61.5 & 66.7 & 32.3 & 60.4 \\
\hline $\begin{array}{l}\text { Dua et al. } \\
\text { (2011) [49] }\end{array}$ & 70.8 & 41.7 & 66.7 & 84.7 & 68.7 & 93.8 \\
\hline $\begin{array}{l}\text { Avalia-T } \\
(2012)[46]\end{array}$ & 88.9 & 70.8 & 79.2 & 75.0 & 49.0 & 60.4 \\
\hline $\begin{array}{l}\text { Mitchell et al. } \\
\text { (2013) [48] }\end{array}$ & 86.1 & 66.7 & 75.0 & 80.6 & 71.9 & 85.4 \\
\hline $\begin{array}{l}\text { Average Domain } \\
\text { Score (SD) }\end{array}$ & $72.1(12.1)$ & $54.5(23.3)$ & $65.8(13.9)$ & 77.0 (11.4) & $41.5(22.6)$ & $59.2(23.7)$ \\
\hline
\end{tabular}

SD Standard Deviation

${ }^{a}$ Includes Grosset et al. [54]

${ }^{b}$ Originally created in 2007 and updated in 2011

c Includes Patel et al. [61]

${ }^{d}$ Includes Moore et al. [62], Herrman et al. [63]

REM sleep behaviour disorder (RBD) $(n=2)[39,40]$. It is recommended to avoid amoxapine and lithium in those with PD, due to the risk of worsening motor symptoms $(n=1)$ [39].

There is some weak evidence supporting the use of dopamine agonists and monoamine oxidase inhibitors for the management of depression in $\mathrm{PD}(n=3)[34,39,40]$. Pramipexole was suggested to have an antidepressant effect not solely due a motor effect [40]. Selegiline has some antidepressant effects but further studies are needed [39]. If the mood symptoms are only present during off periods, it was suggested that patients might benefit from drugs addressing the motor symptoms [34]. However there was no evidence levodopa alone affected mood [40].

Other therapies for depression are not well explored in PD. The European Federation of Neurological Sciences 
Table 3 Statements \& recommendations for Parkinson's disease

\begin{tabular}{|c|c|}
\hline \multicolumn{2}{|l|}{ Anxiety } \\
\hline \multicolumn{2}{|c|}{ Evidence for the Management \& Treatment of Anxiety in PD is Lacking. } \\
\hline Level of Evidence & $\begin{array}{l}\text { AAN Level U } \\
\text { (Uncertain or Lack of Evidence) }\end{array}$ \\
\hline Guidelines & Zesiewicz et al. (2010) [35], Grimes et al. (2012) [34] \\
\hline \multicolumn{2}{|l|}{ Depression } \\
\hline \multicolumn{2}{|c|}{ Screening for Depression in PD is recommended. } \\
\hline Level of Evidence & $\begin{array}{l}\text { EFNS Level A (Effective), SIGN Grade C } \\
\text { (Case Control to Cohort Evidence) }\end{array}$ \\
\hline Guidelines & Berardelli et al. (2013) [38], Grosset et al. (2010) [54] \\
\hline \multicolumn{2}{|c|}{ There are several available tools screening for Depression in PD. } \\
\hline Level of Evidence & $\begin{array}{l}\text { SIGN Level C \& Good Practice Point } \\
\text { (GDS, BDI, HADS, MADRS \& HDRS) \& EFNS } \\
\text { Class I (Diagnostic Accuracy Study)(MDS-UPDRS) }\end{array}$ \\
\hline Guidelines & Grosset et al. (2010) [54], Berardelli et al. (2013) [38] \\
\hline Comment & $\begin{array}{l}\text { A patient with PD should be screened for } \\
\text { depression with either a clinician or self-rated } \\
\text { tool. Diagnosis should not be based on the solely } \\
\text { on the tool. Those with a positive screening test } \\
\text { should be referred for further assessment and } \\
\text { diagnosis (including collateral history). }\end{array}$ \\
\hline \multicolumn{2}{|c|}{ Practitioners should have a low threshold for diagnosing Depression in PD } \\
\hline Level of Evidence & CFNS Good Practice Point \\
\hline Guidelines & Grimes et al. (2012) [34] \\
\hline \multicolumn{2}{|c|}{ Treatment of Depression in PD needs to be individualized to each case. } \\
\hline Level of Evidence & CFNS Good Practice Point \\
\hline Guidelines & Grimes et al. (2012) [34] \\
\hline
\end{tabular}

Anti-depressant Therapy is recommended; there is little evidence to suggest one agent over another.

Guidelines Gelenberg et al. (2010) [39], Grosset et al. (2010) [54]

Tricyclic Antidepressants (e.g. Amitriptyline or Desipramine) have some evidence for treatment, but this must be balanced with the adverse effects (e.g. Anticholinergic).

Level of Evidence

CFNS Level C (Possibly Effective)

Guidelines Grimes et al. (2012) [34], Grosset et al. (2010) [54], Gelenberg et al. (2010) [39]

Selective Serotonin Reuptake Inhibitors have some evidence for treatment, but this must be balanced with the adverse effects (e.g. RLS, PLM, RBD).

EFNS Class II (Prospective Matched Group Cohort Level of Evidence or Controlled Trial) to Class IV (Uncontrolled Studies), APA Level II (Moderate Clinical Evidence)

Guidelines Ferreira et al. (2013) [40], Gelenberg et al. (2010) [39]

Certain agents such as Amoxapine or Lithium should be avoided due to worsening of PD Symptoms.

Guidelines Gelenberg et al. (2010) [39]

There is some evidence for the use of dopamine agonists (e.g. Pramipexole) \& MAOI (e.g. Selegiline) for depression, but not for levodopa.

EFNS Class I (RCT),

Level of Evidence Class III (Other Controlled Trial), APA Level I

(Recommended with substantial confidence)
Table 3 Statements \& recommendations for Parkinson's disease (Continued)

Guidelines Ferreira et al. (2013) [40], Gelenberg et al. (2010) [39], Grimes et al. (2012) [34]

There is insufficient evidence regarding the use of ECT, TCMS and psychotherapy in depression with PD.

Guidelines Ferreira et al. (2013) [40], Gelenberg et al. (2010) [39], Grimes et al. (2012) [34]

(EFNS) concluded there was insufficient data to recommend psychotherapy, electroconvulsive therapy (ECT) or transcranial magnetic stimulation (TCMS) [40]. Other guideline assert that ECT has been used in PD, but that there are no specific trials in PD and is associated with risk $(n=2)[34,39]$.

\section{Dementia recommendations}

It is recommended that patients with dementia be assessed for anxiety $(n=2)$, however there is no clear consensus on what tools to use $[41,42]$. One guideline recommended the use of the Hospital Anxiety Depression Scale [42]. The evidence for the treatment of anxiety in dementia is lacking $(n=1)$ [42].

It is recommended that patients with dementia be evaluated and re-evaluated over time for depression $(n=5)$ [41-45]. As part of this assessment, patients should be evaluated for other secondary causes of depression. It is suggested that these patients be assessed for suicidality by one guideline [39], however another reported there was inconclusive evidence regarding this [46].

The use of a valid screening tool was recommended for depression case finding $(n=5)$ in dementia, including the CSDD, GDS or Dementia Mood Assessment Scale (DMAS) [39, 42, 45, 47, 48]. The CSDD was more commonly recommended given it is a clinician-rating tool that involves caregivers with higher sensitivity $(n=4)$ [39, 45, 47, 48].

Therapy for depression in those with dementia should include a variety of non-pharmacologic options $(n=4)$ such as stimulation oriented, cognitive behavioural, reminiscence, exercise or multi-sensory therapy [39, 41, 42, 48]. Pharmacologic therapy is recommended despite variable evidence $(n=6)$ [41, 42, 44, 45, 49, 50]. It is suggested by one guideline that, if there is no improvement with nonpharmacologic therapy, an antidepressant be considered [50]. Another notes that for moderate-severe depression, pharmacologic treatment is warranted $(n=1)$ [49]. However, there needs to be a clear risk-benefit assessment and discussion $(n=1)$ [41]. Based largely on clinical experience, most guidelines recommend the use of SSRIs given the lower side effect profile over TCAs $(n=6)[39,41,42,45$, $49,50]$. The concern with TCAs is largely anticholinergic side effects causing worsened cognition [42, 50]. Other 
Table 4 Statements \& recommendations for Dementia

Anxiety

Patients with Dementia should be assessed for Anxiety (e.g. HADS).

Level of Evidence

$$
\text { AIAQS Level D (Expert Opinion) }
$$

Guidelines

AIAQS (2010) [42], NICE (2011) [41]

Psychological Interventions can be considered for Anxiety in Dementia

Guidelines

$$
\text { NICE (2011) [41] }
$$

There is little evidence about the treatment of Anxiety in those with Dementia.

Cholinesterase Inhibitors can be considered for treating Dementiarelated behaviours, including anxiety.

Level of Evidence

$$
\text { AIAQS Level A (Meta-analysis or RCT) }
$$

Guidelines $\quad$ AIAQS (2010) [42]

\section{Depression}

Patients experiencing Dementia should be evaluated for Depression, including possible secondary causes.

CRCD Level A (Useful), AIAQS Level D, WFSBP Grade 3 Level of Evidence (Limited Evidence from Controlled Studies), EFNS GPP

$$
\text { Guidelines NICE (2011) [41], AIAQS (2010) [42], CRCD (2011) [43], }
$$$$
\text { Sorbi et al (2012) [45], Ihl et al. (2011) [44] }
$$

Patients with Depression in Dementia should be evaluated for suicide risk, however evidence varies.

$$
\text { APA Level I (Substantial Clinical Confidence) or }
$$

Level of Evidence Inconclusive

$$
\text { Guidelines Gelenberg et al. (2010) [39], Avalia-T (2012) [46] }
$$

Use of a valid screening tool (e.g. CSDD, GDS, HADS or DMAS) for Depression is recommended.

AIAQS Level D to Good Practice Point, Low Quality Level of Evidence Evidence, EFNS GPP/Class II (Prospective Study)

Guidelines Gelenberg et al. (2010) [39], AIAQS (2010) [42], Sorbi et al (2012) [45], Hort et al (2010) [47], Mitchell et al. (2013) [48]

fMRI needs further study to determine its utility in Depression in the context of Dementia

CCCDT4 Grade 2C (Moderate Recommendation, Level of Evidence Low Level Evidence)

\begin{tabular}{|c|c|}
\hline Guidelines & $\begin{array}{l}\text { NICE (2011) [41], AIAQS (2010) [42], Gelenberg et al. } \\
\text { (2010) [39], Mitchell et al. (2013) [48] }\end{array}$ \\
\hline Comment & $\begin{array}{l}\text { These include: cognitive behavioural therapy, } \\
\text { reminiscence therapy, multi-sensory stimulation, } \\
\text { animal-assisted therapy, exercise, stimulation-orientec } \\
\text { treatment (recreational or pleasurable activities), or } \\
\text { improvements to a living situation. Consider } \\
\text { the involvement of carers. }\end{array}$ \\
\hline
\end{tabular}

$$
\text { Guidelines Gauthier et al. (2012) [50] }
$$

Therapy for Depression in Dementia should include a variety of Nonpharmacologic options.

$$
\text { AIAQS Level C (Case-control, Cohort), APA Level II }
$$

Level of Evidence (Moderate Clinical Confidence)

\begin{tabular}{|c|c|}
\hline & $\begin{array}{l}\text { Expert Opinion), WFSBP Grade } 5 \text { (Inconsistent Results), } \\
\text { APA Level II (Moderate Clinical Confidence) }\end{array}$ \\
\hline Guidelines & $\begin{array}{l}\text { Gauthier et al. (2012) [50], NICE (2011) [41], Sorbi et al } \\
\text { (2012) [45], Gelenberg et al. (2010) [39], Ihl et al. (2011) } \\
\text { [44], Dua et al (2011) [49] }\end{array}$ \\
\hline \multicolumn{2}{|c|}{$\begin{array}{l}\text { When choosing an anti-depressant (E.g. SSRIs, SNRIs or TCAs) it is } \\
\text { important to consider the anticholinergic side effects. }\end{array}$} \\
\hline Level of Evidence & $\begin{array}{l}\text { EFNS Level B (Case-control, Cohort), EFNS Class IV } \\
\text { (Un-blinded, Expert Opinion), APA Level I } \\
\text { (Substantial Clinical Confidence) to APA Level II } \\
\text { (Moderate Clinical Confidence), AIAQS Level B }\end{array}$ \\
\hline Guidelines & $\begin{array}{l}\text { Gauthier et al. (2012) [50], NICE (2011) [41], } \\
\text { Sorbi et al (2012) [45], Hort et al (2010) [47], } \\
\text { Gelenberg et al. (2010) [39], AIAQS (2010) [42] }\end{array}$ \\
\hline Comment & $\begin{array}{l}\text { SSRIs (Citalopram or Sertraline) and TCAs have similar } \\
\text { efficacy, but TCAs are not recommended given } \\
\text { anticholinergic effects. SSRIs appear to be better } \\
\text { tolerated. Other agents such as bupropion, } \\
\text { venlafaxine and mirtazapine may be effective. }\end{array}$ \\
\hline \multicolumn{2}{|c|}{ Stimulants can be considered for treatment of Depression in Dementia. } \\
\hline Level of Evidence & $\begin{array}{l}\text { APA Level III (Depends on Individual Circumstances), } \\
\text { AIAQS Level B (Case-control, Cohort) }\end{array}$ \\
\hline Guidelines & Gelenberg et al. (2010) [39], AIAQS (2010) [42] \\
\hline \multicolumn{2}{|c|}{$\begin{array}{l}\text { Cholinesterase Inhibitors can be considered for treating Dementia- } \\
\text { related behaviours, including depression. }\end{array}$} \\
\hline & AIAQS Level A (Meta-analysis or RCT) \\
\hline \multicolumn{2}{|l|}{ Level of Evidence } \\
\hline Guidelines & AIAQS (2010) [42] \\
\hline \multicolumn{2}{|c|}{$\begin{array}{l}\text { ECT can be considered in certain cases for Depression in those with } \\
\text { Dementia. }\end{array}$} \\
\hline \multicolumn{2}{|l|}{ Level of Evidence } \\
\hline Guidelines & Gelenberg et al. (2010) [39] \\
\hline \multicolumn{2}{|c|}{$\begin{array}{l}\text { Cholinesterase Inhibitors may improve neuropsychiatric symptoms in } \\
\text { Lewy Body Disease }\end{array}$} \\
\hline \multicolumn{2}{|l|}{ Level of Evidence } \\
\hline Guidelines & O'Brien et al (2011) [60] \\
\hline
\end{tabular}

Although evidence is mixed, a trial of Anti-depressants could be considered for Depression in Dementia.

CCCDT4 Grade 2A (Moderate Recommendation, Level of Evidence High Level Evidence), EFNS Class IV (Un-blinded,
Table 4 Statements \& recommendations for Dementia (Continued)

antidepressants such as mirtazapine, bupropion, and venlafaxine may also be of benefit $(n=1)$ [42]. Other adjunct therapies recommended include stimulants $(n=2)[39,42]$, cholinesterase inhibitors $(n=1)$ [42] and ECT on a case-by-case basis $(n=1)$ [39].

\section{Discussion}

This study provides a synthesis and quality assessment of available guidelines for the management of depression or anxiety in PD or dementia. We identified clear gaps in guideline quality and the evidence, which inform future research and knowledge translation. 


\section{Guideline quality}

Guidelines that were excluded due to low quality were typically those that lacked explicit development methods, thus ratings across all the domains were low. When examining the AGREE II ratings overall, the lowest rating was in assessing the guideline description of barriers and facilitators, implementation, resource implications, or monitoring/auditing criteria (Domain 5). In fact, few guidelines had discrete sections addressing knowledge translation. The concern about guideline applicability was explored in a 2015 systematic review [51], which found that applicability scored lower than any other domain [51, 52]. If guidelines rarely address their implementation in practice, then there will be continued practice variation. There is clear evidence supporting the use of implementation tools to improve guideline uptake [51]. Thus making guidelines without a clear knowledge translation plan does a disservice to stakeholders [51].

The engagement of patients and caregivers was notably absent in CPG development. This process is important, as it is aimed at improving implementability, by ensuring the recommendations are comprehensive, adaptable and applicable to the target group and have an open process [53]. Given the constant changing nature of evidence, having up-to-date guidelines certainly makes a difference to the validity [32]. However, the lowest rated item was for the guideline update procedures.

\section{Guideline content}

There is an overall lack of recommendations related to the diagnosis or treatment of anxiety in either PD or dementia. This stems from the fact there is little evidence on how to approach the assessment. One guideline suggested the use Hospital Anxiety and Depression Scale for dementia, but they did not provide diagnostic accuracy information or suggestions for implementation [42]. There is also a concern that the medications traditionally used for anxiety can have major adverse effects [35], and there are few studies to guide treatment. Anxiety was less frequently mentioned than depression in the included CPGs, and in some cases was only mentioned in combination with other neuropsychiatric symptoms. The overall lack of evidence for anxiety care in PD and dementia is a major gap in the current research.

Guidance for depression was present in a higher proportion of guidelines. Despite this, there is variability in the reporting of levels of evidence and recommendations (Additional file 3: Figure S1). In some cases the recommendations for depression in PD only had 1 or 2 guidelines supporting them, indicating variance in guideline reporting. In other cases recommendations were vague, which can lead to difficulty with end user interpretation and implementation [36].
It is clear that screening for depression with a validated tool in PD is recommended, although evidence varies $[37,38]$. It is recommended, as a good practice point, that any diagnosis of depression is not made solely on a brief assessment tool, as these tools are more focused on case finding [37]. Although this is an important concept in detection, it was only recommended by one guideline [54]. A 2015 systematic review identified several validated tools for the detection of depression in $\mathrm{PD}$, with the GDS-15 having the highest pooled sensitivity $(0.81$; $95 \%$ CI 0.64, 0.91) and area under the curve (0.94) [55].

Recommendations surrounding non-pharmacologic therapy were few, stating there was insufficient evidence for the use of psychotherapy, ECT or TMS [34, 39, 40]. Two recent trials demonstrated the effectiveness of cognitive behavioural therapy in PD [56, 57]. This highlights the need for further large high quality studies on a range of non-pharmacologic therapies and the need for constant update of guidelines. Pharmacological therapy is recommended for managing depression in $\mathrm{PD}$, but there is little evidence on choosing agents [39, 54]. This has resulted in a variety of treatment recommendations, with little evidence to direct clinical practice.

Depression in dementia was more frequently addressed. However, these recommendations also had varied guideline and evidentiary support. Guidelines supported the evaluation of depression in dementia, but evidence ranged from high quality to good practice points [41-45]. Commonly recommended tools were the CSDD and GDS, with preference towards the CSDD due to better accuracy $[39,42,45,47,48]$. This was confirmed by a 2015 systematic review of depression tools for dementia, finding that the CSDD had a area under the curve of 0.89 [58].

Interestingly, the issue of evaluating for suicide risk was raised in two guidelines with divergent recommendations $[39,46]$. One stating there was inconclusive evidence [46] and another stating substantial evidence [39]. It is unclear why there is such a difference in reported evidence; perhaps development groups have different evidence available or differing interpretations of the evidence.

There are stronger recommendations for nonpharmacologic treatment in dementia than in PD, outlining several options $[41,42,45,47,48]$. The evidence for pharmacologic therapy is described as mixed with Grade 2A (Moderate Recommendation, High Level Evidence) to Class IV (Un-blinded Study, Expert Opinion) [39, 41, 44, 45, 49, 50]. Again SSRIs and TCAs are the focus, with TCAs being less likely to be recommended due to side effects [39, 42, 45, 47, 50]. For those with dementia, there were more options recommended for therapy including stimulants, cholinesterase inhibitors and ECT $[39,42]$. 


\section{Limitations}

There is a well-recognized issue with heterogeneity in the terms used to refer to guidelines [52]. For our database search we used indexed terms from each of the three databases as well as key words using known nomenclature for guidelines and the comorbidities. It is also possible that the addition of the depression or anxiety criteria to the search may have been restrictive, however without these terms the search was impractical. To address this, we developed the search strategy with experts in the area of guideline systematic review and an experienced librarian, and we had an external reviewer independently assess the search strategy. To reduce the risk of missing literature not indexed in databases we contacted experts, searched references of included studies and performed an extensive search of the grey literature search.

\section{Conclusions}

Given the burden of comorbid mental illness in dementia and PD, it is key that we understand clearly the current knowledge base so we can improve care for these populations. This study provides a synthesis and quality assessment of the relevant guidelines. By synthesizing the recommendations, we identified areas of knowledge that are potentially ready to be translated into practice but also clear evidence gaps. This data was further evaluated in a subsequent study by stakeholders in focus groups to understand the other barriers and facilitators to the use of guidelines. This was to inform and help develop a comprehensive knowledge/end-user focused plan for addressing these gaps.

\section{Additional files}

Additional file 1: Box S1. Search Strategy. (DOCX $22 \mathrm{~kb})$

Additional file 2: Table S1. Grey Literature Sources ( $n=83)$. (DOCX $15 \mathrm{~kb}$ )

Additional file 3: Figure S1. Evidence Levels \& Grading Schemes Used Across Guidelines [34-49, 59]. (DOCX 65.4 kb)

Additional file 4: Table S2. Mean Domain Question Scores From AGREE II Evaluation. (DOCX $16 \mathrm{~kb}$ )

\footnotetext{
Abbreviations

AAN: American Academy of Neurology; APA: American Psychiatric Association; AIAQS: Agency for Health Quality and Assessment of Catalonia; Avalia-T: Galician Health Technology Assessment Agency; BDI: Beck Depression Inventory; BPA: British Association of Psychopharmacology; CADASIL: Cerebral Autosomal-Dominant Arteriopathy with Subcortical Infarcts and Leukoencephalopathy; CCCDTD4: Canadian Consensus Conference on the Diagnosis and Treatment of Dementia; CNSF: Canadian Neurological Sciences Foundation; CPG: Clinical Practice Guideline; CRCD: Clinical Research Centre for Dementia; CSDD: Cornell Scale for Depression in Dementia; DMAS: Dementia Mood Assessment Scale; ECT: Electroconvulsive Therapy; EFNS: European Federation of Neuroscience; GDS: Geriatric Depression Scale; GRADE: Grading of Recommendations Assessment, Development and Evaluation; HADS: Hospital Anxiety and Depression Scale; HDRS: Hamilton Depression Rating Scale; ICSI: Institute for Clinical Systems Improvement; MADRS: Montgomery Åsberg Depression Rating Scale; MDS: Movement Disorders Society; NICE: National Institute of
}

Clinical Excellence; PD: Parkinson's Disease; PLM: Periodic Limb Movement Syndrome; PRESS: Peer Review of Electronic Search Strategies;

PRISMA: Preferred Reporting Items for Systematic Reviews and MetaAnalyses; RBD: REM Sleep Behaviour Disorder; RCT: Randomized Control Trial; REM: Rapid Eye Movement; RLS: Restless Legs Syndrome; SD: Standard Deviation; SIGN: Scottish Intercollegiate Guidelines Network; SSRI: Selective Serotonin Reuptake Inhibitor; TCA: Tricyclic Acid Antidepressants;

TCMS: Transcranial Magnetic Stimulation; UPDRS: Unified Parkinson's Disease Rating Scale; WFBSP: World Federation of Societies of Behavioural Psychiatry; WHO: World Health Organization

\section{Acknowledgements}

The authors would like to thank Diane Lorenzetti MLS, Research Librarian (DL) for her input into the search strategy, and Helen Lee Robertson MLIS, Liaison Librarian for Clinical Medicine for her (Peer Review of Electronic Search Strategies) PRESS review of our search strategy.

\section{Funding}

This project had funding from an Alberta Innovates Health Solutions-Knowledge to Action Grant.

\section{Availability of data and material}

The datasets during and/or analysed during the current study available from the corresponding author on reasonable request. All data from this study are presented in detail. For the quality assessment the individual ratings are not published as the AGREE group recommends publication $f$ the mean scaled domain scores. The extracted recommendations are summarized in the tables and text, full details are available in the source guidelines.

\section{Authors' contributions}

ZG and BM performed all citation/full text screening, quality assessments, data extraction and analysis and drafted the manuscript. ZG completed all statistical analysis. SG was involved in the grey literature search and quality assessment. JHL supervised all parts of the systematic review and analysis, was involved in the quality assessment and determination of inclusion. ZG, $\mathrm{BM}, \mathrm{SG}, \mathrm{HH}, \mathrm{SS}, \mathrm{TP}, \mathrm{NJ}$ and JHL provided input and reviewed the proposal, protocol, analysis and manuscript. ZG registered the protocol with PROSPERO [58]. All authors had access to the data, reviewed and approved the final manuscript. ZG and JHL had full access to the data in the study and take responsibility for the integrity of the data and accuracy of the data.

\section{Competing interests}

ZG has received funding by Canadian Institutes for Health Research-Canadian Graduate Student Scholarship, Alberta Innovates Health Solutions Clinician Fellowship Award, Canadian Society for Clinical Investigation Resident Research Award, Alberta Student and Western Regional Training Centre affiliate award. BM and SG report no disclosures. $\mathrm{HH}$ has no disclosures. SP holds funding from Hotchkiss Brain Institute (HBI), $\mathrm{ClHR}$ and a grant co-funded by the University of Calgary $\mathrm{HBI}$ and Pfizer Canada. TP has an unrestricted educational grants from Shire Canada. TP has research grant support from Sick Kids Foundation, Alberta Health Services Mental Health Strategic Clinical Network, Hotchkiss Brain Institute and Canadian Institutes for Health Research. NJ holds a Canada Research Chair Tier 2 in Health Services Research and is on the editorial board of Neurology and holds research grants from the Canadian Institutes of Health Research, Alberta Innovates Health Solutions, the Alberta Spine Foundation, the University of Calgary Cumming School of Medicine, Department of Clinical Neurosciences and HBls and a grant co-funded by the University of Calgary $\mathrm{HBI}$ and Pfizer Canada. JHL has received funding from Alberta Health Services as the Scientific Director of the Seniors Health Strategic Clinical Network.

\section{Consent for publication}

Not Applicable.

Ethics approval and consent to participate

University of Calgary Conjoint Health Research Ethics Board (CHREB) REB 14-1449

\section{Author details}

${ }^{1}$ Department of Community Health Sciences, University of Calgary, Calgary, Canada. ${ }^{2}$ Department of Medicine, University of Calgary and Alberta Health 
Services, Calgary, Canada. ${ }^{3}$ Faculty of Medicine, Undergraduate Medical Education, University of Toronto, Toronto, Canada. ${ }^{4}$ Seniors Health Strategic Clinical Network, Alberta Health Services, Alberta, Canada. ${ }^{5}$ Department of Clinical Neurosciences, University of Calgary, Calgary, Canada. ${ }^{6}$ Hotchkiss Brain Institute, and O'Brien Institute for Public Health, University of Calgary and Alberta Health Services, Calgary, Canada. 'Department of Psychiatry and Pediatrics, University of Calgary and Alberta Health Services, Calgary, Canada. ${ }^{8}$ Department of Psychiatry, University of Calgary and Alberta Health Services, Calgary, Canada. ${ }^{9}$ Mathison Centre for Mental Health Research and Education, University of Calgary, Calgary, Canada. ${ }^{10} \# 1104-S o u t h$ Tower. Foothills Medical Centre 3301 Hospital Drive, Calgary, NW T2N 2T9, Canada.

Received: 30 June 2016 Accepted: 10 November 2016 Published online: 25 November 2016

\section{References}

1. Pachana NA, Egan SJ, Laidlaw K, Dissanayaka N, Byrne GJ, Brockman S, Marsh R, Starkstein S. Clinical issues in the treatment of anxiety and depression in older adults with Parkinson's disease. Movement disorders: official journal of the Movement Disorder Society. 2013;28(14):1930-4.

2. Reijnders JS, Ehrt U, Weber WE, Aarsland D, Leentjens AF. A systematic review of prevalence studies of depression in Parkinson's disease. Mov Disord. 2008;23(2):183-9. quiz 313.

3. Schrag A, Leentjens AF. Parkinson disease: scales to detect depression in Parkinson disease. Nat Rev Neurol. 2012;8(7):359-60.

4. Weintraub D, Moberg PJ, Duda JE, Katz IR, Stern MB. Effect of psychiatric and other nonmotor symptoms on disability in Parkinson's disease. J Am Geriatr Soc. 2004;52(5):784-8.

5. Kostic VS, Pekmezovic T, Tomic A, Jecmenica-Lukic M, Stojkovic T, Spica V Svetel M, Stefanova E, Petrovic I, Dzoljic E. Suicide and suicidal ideation in Parkinson's disease. J Neurol Sci. 2010;289(1-2):40-3.

6. Hughes TA, Ross HF, Mindham RH, Spokes EG. Mortality in Parkinson's disease and its association with dementia and depression. Acta Neurol Scand. 2004;110(2):118-23.

7. Orgeta V, Qazi A, Spector AE, Orrell M. Psychological treatments for depression and anxiety in dementia and mild cognitive impairment. Cochrane Database Syst Rev. 2014;1:CD009125.

8. Banerjee S, Hellier J, Dewey M, Romeo R, Ballard C, Baldwin R, Bentham P, Fox C, Holmes C, Katona C, et al. Sertraline or mirtazapine for depression in dementia (HTA-SADD): a randomised, multicentre, double-blind, placebocontrolled trial. Lancet. 2011:378(9789):403-11.

9. Enache D, Winblad B, Aarsland D. Depression in dementia: epidemiology, mechanisms, and treatment. Curr Opin Psychiatry. 2011;24(6):461-72.

10. Riley RJ, Burgener S, Buckwalter KC. Anxiety and stigma in dementia: a threat to aging in place. Nurs Clin North Am. 2014;49(2):213-31.

11. Van der Mussele S, Bekelaar K, Le Bastard N, Vermeiren Y, Saerens J, Somers N, Marien P, Goeman J, De Deyn PP, Engelborghs S. Prevalence and associated behavioral symptoms of depression in mild cognitive impairment and dementia due to Alzheimer's disease. Int J Geriatr Psychiatry. 2013;28(9):947-58.

12. Dissanayaka NN, Sellbach A, Matheson S, O'Sullivan JD, Silburn PA, Byrne GJ, Marsh R, Mellick GD. Anxiety disorders in Parkinson's disease: prevalence and risk factors. Mov Disord. 2010;25(7):838-45.

13. Marsh L. Depression and Parkinson's disease: current knowledge. Curr Neurol Neurosci Rep. 2013;13(12):409.

14. Djamshidian A, Friedman JH. Anxiety and depression in Parkinson's disease. Curr Treat Options Neurol. 2014;16(4):285.

15. Knapskog $A B$, Barca ML, Engedal K. A comparison of the validity of the Cornell Scale and the MADRS in detecting depression among memory clinic patients. Dement Geriatr Cogn Disord. 2011;32(4):287-94.

16. Modrego PJ, Ferrandez J. Depression in patients with mild cognitive impairment increases the risk of developing dementia of Alzheimer type: a prospective cohort study. Arch Neurol. 2004;61(8):1290-3.

17. Ownby RL, Crocco E, Acevedo A, John V, Loewenstein D. Depression and risk for Alzheimer disease: systematic review, meta-analysis, and metaregression analysis. Arch Gen Psychiatry. 2006;63(5):530-8.

18. Frisina PG, Borod JC, Foldi NS, Tenenbaum HR. Depression in Parkinson's disease: health risks, etiology, and treatment options. Neuropsychiatr Dis Treat. 2008;4(1):81-91.

19. Davis D, J. Goldman, P. Valerie: Handbook on Clinical Practice Guidelines. In.: Canadian Medical Association; 2007.
20. Gagliardi AR, Brouwers MC, Palda VA, Lemieux-Charles L, Grimshaw JM. How can we improve guideline use? A conceptual framework of implementability. Implementation Sci. 2011;6:26. https://www.ncbi.nlm.nih.gov/pubmed/ 21426574

21. Graham R, Mancher M, Miller-Wolman D, Greenfield S, Steinberg EH. Clinical Practice Guidelines We Can Trust. Washington: Institute of Medicine (US) Committee on Standards for Developing Trustworthy Clinical Practice Guidelines. National Academy of Sciences; 2011.

22. Grimshaw JM, Thomas RE, MacLennan G, Fraser C, Ramsay CR, Vale L, Whitty $P$, Eccles MP, Matowe L, Shirran L, et al. Effectiveness and efficiency of guideline dissemination and implementation strategies. Health Technol Assess. 2004;8(6):iii-iv. 1-72.

23. Ramasubbu R, Taylor VH, Samaan Z, Sockalingham S, Li M, Patten S, Rodin G, Schaffer A, Beaulieu S, Mclntyre RS, et al. The Canadian Network for Mood and Anxiety Treatments (CANMAT) task force recommendations for the management of patients with mood disorders and select comorbid medical conditions. Ann Clin Psychiatry. 2012;24(1):91-109.

24. Ramasubbu R, Beaulieu S, Taylor VH, Schaffer A, McIntyre RS, Canadian Network for M, Anxiety Treatments Task F. The CANMAT task force recommendations for the management of patients with mood disorders and comorbid medical conditions: diagnostic, assessment, and treatment principles. Ann Clin Psychiatry. 2012;24(1):82-90.

25. Kerr MP, Mensah S, Besag F, de Toffol B, Ettinger A, Kanemoto K, Kanner A Kemp S, Krishnamoorthy E, LaFrance Jr WC, et al. International consensus clinical practice statements for the treatment of neuropsychiatric conditions associated with epilepsy. Epilepsia. 2011;52(11):2133-8.

26. Wilcock J, lliffe S, Turner S, Bryans M, O'Carroll R, Keady J, Levin E, Downs M. Concordance with clinical practice guidelines for dementia in general practice. Aging Ment Health. 2009;13(2):155-61.

27. Salter K, McClure JA, Mahon H, Foley N, Teasell R. Adherence to Canadian best practice recommendations for stroke care: assessment and management of poststroke depression in an Ontario rehabilitation facility. Top Stroke Rehabil. 2012;19(2):132-40.

28. McCluskey A, Vratsistas-Curto A, Schurr K. Barriers and enablers to implementing multiple stroke guideline recommendations: a qualitative study. BMC Health Serv Res. 2013;13:323.

29. Moher D, Liberati A, Tetzlaff J, Altman DG, Group P. Preferred reporting items for systematic reviews and meta-analyses: the PRISMA statement. Bmj 2009, 339:b2535.

30. Making the Case for Investing in Mental Health in Canada. In.: Mental Health Commission of Canada; 2013.

31. PRESS: peer review of electronic search strategies. 2015 Guideline Explanation and Elaboration (PRESS E\&E). Ottawa: Canadian Agency for Drugs and Technologies in Health; 2016. https://www.cadth.ca/sites/default/ files/pdf/CP0015_PRESS_Update_Report_2016.pdf

32. Martinez Garcia L, Sanabria AJ, Garcia Alvarez E, Trujillo-Martin MM, Etxeandia-Ikobaltzeta I, Kotzeva A, Rigau D, Louro-Gonzalez A, Barajas-Nava L, Diaz Del Campo P, et al. The validity of recommendations from clinical guidelines: a survival analysis. CMAJ. 2014;186(16):1211-9.

33. Brouwers MC, Kho ME, Browman GP, Burgers JS, Cluzeau F, Feder G, Fervers B, Graham ID, Grimshaw J, Hanna SE, et al. AGREE II: advancing guideline development, reporting and evaluation in health care. CMAJ. 2010;182(18): E839-842.

34. Grimes D, Gordon J, Snelgrove B, Lim-Carter I, Fon E, Martin W, Wieler M, Suchowersky O, Rajput A, Lafontaine AL, et al. Canadian guidelines on Parkinson's disease. Can J Neurol Sci. 2012;39(4 Suppl 4):S1-30.

35. Zesiewicz TA, Sullivan KL, Arnulf I, Chaudhuri KR, Morgan JC, Gronseth GS, Miyasaki J, Iverson DJ, Weiner WJ, Quality Standards Subcommittee of the American Academy of N. Practice parameter: treatment of nonmotor symptoms of Parkinson disease: report of the quality standards subcommittee of the American Academy of Neurology. Neurology. 2010; 74(11):924-31.

36. Michie $\mathrm{S}$, Johnston M: Changing clinical behaviour by making guidelines specific. Bmj 2004, 328(7435):343-345.

37. Diagnosis and pharmacological management of Parkinson's disease: A national clinical guideline. Scottish Intercollegiate Guidelines Network; 2010.

38. Berardelli A, Wenning GK, Antonini A, Berg D, Bloem BR, Bonifati V, Brooks D, Burn DJ, Colosimo C, Fanciulli A, et al. EFNS/MDS-ES/ENS [corrected] recommendations for the diagnosis of Parkinson's disease. European journal of neurology: the official journal of the European Federation of Neurological Societies. 2013;20(1):16-34 
39. Gelenberg AJ, Freeman MP, Markowitz JC, Rosenbaum JF, Thase ME, Trivedi $\mathrm{MH}$, Van Rhoads RS. Practice Guideline for Treatment of Patients with Major Depressive Disorder 3rd Edition. American Pyschiatric Association; 2010.

40. Ferreira JJ, Katzenschlager R, Bloem BR, Bonuccelli U, Burn D, Deuschl G, Dietrichs E, Fabbrini G, Friedman A, Kanovsky P, et al. Summary of the recommendations of the EFNS/MDS-ES review on therapeutic management of Parkinson's disease. Eur J Neurol. 2013;20(1):5-15. https://www.ncbi.nlm. nih.gov/pubmed/23279439

41. Dementia: Guidelines on Supporting People with Dementia and their carers in Health and Social Care. National Institute for Health and Clinical Excellence. National Collaborating Centre for Mental Health. Social Care Institute for Excellence National Institute for Health and Clinical Excellence. In. London: The British Psychological Society \& Gaskell The Royal College of Psychiatrists; 2011

42. Development Group of the Clinical Practice Guideline on the comprehensive care of people with Alzheimer's disease and other dementias. Clinical Practice Guideline on the comprehensive care of people with Alzheimer's disease and other dementias. Quality Plan for the National Health System of the Ministry of Health, Social Policies and Equality Agència d'Informació, Avaluació i Qualitat en Salut of Catalonia Clinical Practice Guidelines in the Spanish National Health Service: AIAQS No 2009/07 2010. http://www.guiasalud.es/GPC/GPC_484_Alzheimer_AIAQS_comp_eng.pdf

43. Clinical Research Center for Dementia of South Korea. Clinical practice guideline for dementia. Part I: diagnosis \& evaluation. Seoul: Clinical Research Center for Dementia of South Korea; 2011. p. 117. The guideline cited is available here: http://jkma.org/src/SM/jkma-54-861-s002.pdf

44. Ihl R, Frolich L, Winblad B, Schneider L, Burns A, Moller HJ, Disease WTFoTGfAs, other D. World Federation of Societies of Biological Psychiatry (WFSBP) guidelines for the biological treatment of Alzheimer's disease and other dementias. World J Biol Psychiatry. 2011;12(1):2-32. https://www.ncbi. nlm.nih.gov/pubmed/21288069

45. Sorbi S, Hort J, Erkinjuntti T, Fladby T, Gainotti G, Gurvit H, Nacmias B, Pasquier F, Popescu BO, Rektorova I, et al. EFNS-ENS Guidelines on the diagnosis and management of disorders associated with dementia. Eur J Neurol. 2012;19(9):1159-79. https://www.ncbi.nlm.nih.gov/pubmed/ 22891773

46. Working Group of the Clinical Practice Guideline for the Prevention and Treatment [trunc]. Clinical practice guideline for the prevention and treatment of suicidal behaviour. Madrid: Ministry of Health and Social Policy, Galician Health Technology Assessment Agency; 2012. p. 382. http://www. guiasalud.es/GPC/GPC_481_Conducta_Suicida_Avaliat_compl_en.pdf

47. Hort J, O'Brien JT, Gainotti G, Pirttila T, Popescu BO, Rektorova I, Sorbi S, Scheltens P, Dementia ESPo. EFNS guidelines for the diagnosis and management of Alzheimer's disease. Eur J Neurol. 2010;17(10):1236-48.

48. Mitchell J, Trangle M, Degnan B, Gabert T, Haight B, Kessler D, Mack N, Mallen E, Novak H, Rossmiller D, et al. Adult Depression in Primary Care. Institute for Clinical Systems Improvement; 2013.

49. Dua T, Barbui C, Clark N, Fleischmann A, Poznyak V, van Ommeren M, Yasamy MT, Ayuso-Mateos JL, Birbeck GL, Drummond C, et al. Evidencebased guidelines for mental, neurological, and substance use disorders in low- and middle-income countries: summary of WHO recommendations. PLoS Med. 2011;8(11):e1001122. https://www.ncbi.nlm.nih.gov/pubmed/ 22110406

50. Gauthier S, Patterson C, Chertkow H, Gordon M, Herrmann N, Rockwood K, Rosa-Neto P, Soucy JP. Recommendations of the 4th Canadian consensus conference on the diagnosis and treatment of dementia (CCCDTD4). Can Geriatr J. 2012;15(4):120-6.

51. Gagliardi AR, Brouwers MC. Do guidelines offer implementation advice to target users? A systematic review of guideline applicability. BMJ Open. 2015; 5(2):e007047.

52. Sauro KM, Wiebe S, Dunkley C, Janszky J, Kumlien E, Moshe S, Nakasato N, Pedley TA, Perucca E, Senties H, et al. The current state of epilepsy guidelines: A systematic review. Epilepsia. 2016;57(1):13-23.

53. Eccles MP, Grimshaw JM, Shekelle P, Schunemann HJ, Woolf S. Developing clinical practice guidelines: target audiences, identifying topics for guidelines, guideline group composition and functioning and conflicts of interest. Implementation Sci. 2012;7:60.

54. Grosset DG, Macphee GJ, Nairn M, Guideline Development G. Diagnosis and pharmacological management of Parkinson's disease: summary of SIGN guidelines. BMJ. 2010;340:b5614.
55. Goodarzi ZS, Mrklas K, Roberts DJ, Jette N, Pringsheim T, Holroyd-Leduc J. Depression case finding in Parkinson's disease patients: a systematic review of depression screening tools. Montreal: Canadian Geriatric Society Scientific Meeting 2015; 2015.

56. Dobkin RD, Menza M, Allen LA, Gara MA, Mark MH, Tiu J, Bienfait KL, Friedman J. Cognitive-behavioral therapy for depression in Parkinson's disease: a randomized, controlled trial. Am J Psychiatry. 2011;168(10):1066-74.

57. Troeung L, Egan SJ, Gasson N. A waitlist-controlled trial of group cognitive behavioural therapy for depression and anxiety in Parkinson's disease. BMC Psychiatry. 2014;14:19.

58. Goodarzi Z, Mele B, Roberts D, Holroyd-Leduc J. Depression case finding in dementia patients: a systematic review of depression screening tools. Ottawa: Canadian Conference on Dementia Meeting 2015; 2015.

59. Guidance notes for registering a systematic review protocol with PROSPERO. In: PROSPERO: International prospective register of systematic reviews Centre for Reviews and Dissemination, National Institute for Health Research; 2013.

60. O'Brien JT, Burns A, Group BAPDC. Clinical practice with anti-dementia drugs: a revised (second) consensus statement from the British Association for Psychopharmacology. J Psychopharmacol. 2011;25(8):997-1019. https:// www.ncbi.nlm.nih.gov/pubmed/21088041

61. Patel T, Chang F, Parkinson Society C. Parkinson's disease guidelines for pharmacists. Can Pharm J. 2014;147(3):161-70.

62. Moore A, Patterson C, Lee L, Vedel I, Bergman H, Canadian Consensus Conference on the D, Treatment of D. Fourth Canadian Consensus Conference on the Diagnosis and Treatment of Dementia: recommendations for family physicians. Can Fam Physician. 2014;60(5):433-8.

63. Herrmann N, Lanctot KL, Hogan DB. Pharmacological recommendations for the symptomatic treatment of dementia: the Canadian Consensus Conference on the Diagnosis and Treatment of Dementia 2012. Alzheimer's Res Ther. 2013;5 Suppl 1:S5. https://www.ncbi.nlm.nih.gov/pubmed/ 24565367

64. Rabins PV, Blacker D, Rovner BW, Rummans T, Schneider LS, Tariot PN, Blass DM. Practice Guidelines for the Treatment of Patients With Alzheimer's Disease and Other Dementias. American Pyschiatric Association; 2007.

\section{Submit your next manuscript to BioMed Central and we will help you at every step:}

- We accept pre-submission inquiries

- Our selector tool helps you to find the most relevant journal

- We provide round the clock customer support

- Convenient online submission

- Thorough peer review

- Inclusion in PubMed and all major indexing services

- Maximum visibility for your research

Submit your manuscript at www.biomedcentral.com/submit
C Biomed Central 